\title{
Less invasive surfactant administration: all that glitters is not gold
}

\author{
Daniele De Luca ${ }^{1,2} \cdot$ J. Peter de Winter ${ }^{3,4}$
}

Published online: 27 May 2020

(C) Springer-Verlag GmbH Germany, part of Springer Nature 2020

Keywords Surfactant $\cdot$ Intubation $\cdot$ Neonate $\cdot$ Prematurity $\cdot$ Respiratory distress syndrome $\cdot$ INSURE $\cdot$ MIST

\begin{abstract}
Abbreviations
INSURE intubation-surfactant-extubation

LISA invasive surfactant administration

MIST minimally invasive surfactant treatment

NIPPV noninvasive positive pressure ventilation

RDS respiratory distress syndrome
\end{abstract}

In the last decade, techniques supposed to provide a less invasive surfactant administration have been proposed to treat respiratory distress syndrome (RDS), and the interest in these methods has spread. These techniques are supposed to find a place within the general drive toward the reduction in the aggressiveness of neonatal critical care whenever it is possible.

However, the so-called less invasive surfactant administration (LISA) or minimally invasive surfactant treatment (MIST) techniques represent an example of unjustified enthusiasm, as there is a lack of physiopathological and biological background supporting their hypothetical benefits [1]. These techniques have gained diffusion without following the clear regulatory pathway that should be required for innovative therapeutic methods [2] and have been tested in just a few

See related article, https://doi.org/10.1007/s00431-020-03682-9

Communicated by Daniele De Luca

Daniele De Luca

dm.deluca@icloud.com

1 Division of Pediatrics and Neonatal Critical Care, "A.Béclère" Medical center, Paris Saclay University Hospital-APHP, Clamart, France

2 Physiopathology and Therapeutic Innovation Unit-INSERM U999, Paris Saclay University, Paris, France

3 Department of Pediatrics, Spaarne Gasthuis, Hoofddorp/ Haarlem, The Netherlands

4 Department of Development and Regeneration, KU Leuven, Leuven, Belgium trials, which were not free from relevant biases. Any trial or research project has limitations, but the majority of those investigating less invasive surfactant administration techniques are affected by similar flaws, and the main ones are $[1,3]$ :

- differences in sedation policies between the study arms;

- unstandardized surfactant dose;

- unclear thresholds of pressure and inspired oxygen to administer surfactant;

- lack of comparison between the new technique and the real intubation-surfactant-extubation (INSURE) technique (that is, a short, gentle, volume-controlled ventilation).

Moreover, a common outcome in these trials was the need for invasive ventilation. Still, this endpoint, if considered all along with the hospital stay, may be influenced by a panoply of cofactors that are unrelated to surfactant replacement for RDS and that may occur well after the first days of life (for instance: hemodynamic derangements, central neurological problems, feeding troubles/necrotizing enterocolitis, availability of different noninvasive support techniques, late-onset sepsis etc..).

Gupta et al., in this number of the Journal published a randomized controlled trial that, for the first time, is significantly unaffected by some of the aforementioned biases [4]. Patients in this trial have not been subjected to any pharmacological sedation; thus the respiratory drive is not affected by the application of different sedation policies in the two study arms. Surfactant dose and thresholds for its administration were standardized and consistent between the arms, while surfactant was given early, as suggested to optimize its effect [5]. Most importantly, Gupta et al. compared less invasive surfactant administration with a real INSURE, at least in terms of duration, as ventilation during INSURE lasted on average $182 \mathrm{~s}$. Concerning this issue, the Gupta's study is superior to the first multicenter trial on LISA where only $33 \%$ of neonates in the control arm were extubated within the first $24 \mathrm{~h}(77 \%$ were continuously ventilated beyond the first day of life) [6]. The comparison is not perfect as INSURE has been performed 
by bagging, and this cannot provide any control on volume and pressure delivery. However, this may be understandable in a developing country and particular settings where ventilator with volume guarantee modalities are not always available. The absence of pharmacological sedation is also not advisable based on international recommendations [7, 8].

However, the Gupta's study clearly demonstrates that, when INSURE is well done in terms of duration, and when there is no bias due to different sedation in the two study arms, the administration of surfactant through narrow, nonventilable catheters does not provide any advantage. This seems logical since a short ventilation is unlikely to trigger a significant ventilator-induced lung injury, as suggested by a bunch of animal and clinical studies both in adults and neonates $[1,9]$.

Another advantage of the Gupta's trial is the clear identification of a solid outcome, that is, the need for intubation within the first $72 \mathrm{~h}$ of life, which seems to occur with a reasonable frequency, according to current standard of care. This outcome is chronologically and physiopathologically related to the trial intervention, while other LISA trials focused on a more general need for intubation and/or duration of invasive ventilation $[6,10]$. These are much widely variable and weaker outcomes, as intubation in NICU-admitted preterm neonates can occur far from the surfactant replacement and may be physiopathologically unrelated to the trialed intervention (see above) [1].

Finally, Gupta and colleagues provide insights about the use of noninvasive positive pressure ventilation (NIPPV) during surfactant administration. Experimental data show that continuous positive airway pressure is poorly (or not) transmitted during LISA, due to the airflow limitation [11], and that airway resistances are increased [12]. This may be the cause for bradycardia and desaturations frequently observed during LISA techniques [1]. In adult critical care, analogous problems have been overcome by using NIPPV $[12,13]$ and a previous trial suggested similar benefits in neonates undergoing LISA [14]. The Gupta's trial confirms that NIPPV is feasible during surfactant administration and that, although this was not within the study purposes, NIPPV might helpful during LISA.

This trial also has some limitations, such as the single center design and the small enrolled population, beside the peculiar setting, which may reduce the generalizability of results. However, it goes toward the right direction providing insight about how to understand and eventually improve LISA techniques.

In conclusion, clinicians should not only follow what is newer and seems fancy but rather are advised to deeply analyze complex problems that are unlikely to have simple solutions. LISA techniques represent a perfect example of this, and accurately designed studies are needed. Gupta's trial is a significant step forward, as it demonstrates that all that glitters is not gold.

\section{References}

1. De Luca D, Shankar-Aguilera S, Centorrino R et al (2020) Less invasive surfactant administration: a word of caution. Lancet Child Adolesc Health 4:331-340. https://doi.org/10.1016/S23524642(19)30405-5

2. US Food and Drug Administration. General considerations for animal studies for medical devices: draft guidance for industry food and drug administration staff. Oct 14, 2015. https://www.fda.gov/ media/93963/download. Accessed on 10 May 2020

3. Foligno S, De Luca D (2019) Carelessness about surfactant dosea cultural problem, a legal issue, or an open research question? JAMA Pediatr 173:211. https://doi.org/10.1001/jamapediatrics. 2018.4296

4. Gupta B, Saha A, Mukherjee S, Saha B Minimally invasive surfactant therapy versus InSurE in preterm neonates of 28 to 34 weeks with respiratory distress syndrome on noninvasive positive pressure ventilation - a randomized controlled trial. Eur J Pediatr. https://doi. org/10.1007/s00431-020-03682-9

5. Bahadue FL, Soll R (2012) Early versus delayed selective surfactant treatment for neonatal respiratory distress syndrome. Cochrane Database Syst Rev 11:CD001456. https://doi.org/10.1002/ 14651858.CD001456.pub2

6. Göpel W, Kribs A, Ziegler A et al (2011) Avoidance of mechanical ventilation by surfactant treatment of spontaneously breathing preterm infants (AMV): an open-label, randomised, controlled trial. Lancet 378:1627-1634. https://doi.org/10.1016/S0140-6736(11) 60986-0

7. Ancora G, Lago P, Garetti E et al (2019) Evidence-based clinical guidelines on analgesia and sedation in newborn infants undergoing assisted ventilation and endotracheal intubation. Acta Paediatr 108: 208-217. https://doi.org/10.1111/apa.14606

8. Kumar P, Denson SE, Mancuso TJ, Committee on Fetus and Newborn, Section on Anesthesiology and Pain Medicine (2010) Premedication for nonemergency endotracheal intubation in the neonate. Pediatrics 125:608-615. https://doi.org/10.1542/peds. 2009-2863

9. Dell'Orto V, Bourgeois-Nicolaos N, Rouard C et al (2018) Cell count analysis from nonbronchoscopic bronchoalveolar lavage in preterm infants. J Pediatr 200:30-37.e2. https://doi.org/10.1016/j. jpeds.2018.04.074

10. Halim A, Shirazi H, Riaz S et al (2019) Less invasive surfactant administration in preterm infants with respiratory distress syndrome. J Coll Physicians Surg Pak 29:226-330. https://doi.org/10. 29271/jcpsp.2019.03.226

11. Jourdain G, De Tersant M, Dell'Orto V et al (2018) Continuous positive airway pressure delivery during less invasive surfactant administration: a physiologic study. J Perinatol 38:271-277. https://doi.org/10.1038/s41372-017-0009-3

12. Antonelli M, Conti G, Riccioni L, Meduri GU (1996) Noninvasive positive-pressure ventilation via face mask during bronchoscopy with BAL in high-risk hypoxemic patients. Chest 110:724-728. https://doi.org/10.1378/chest.110.3.724

13. Antonelli M, Conti G, Rocco M et al (2002) Noninvasive positivepressure ventilation vs conventional oxygen supplementation in hypoxemic patients undergoing diagnostic bronchoscopy. Chest 121:1149-1154. https://doi.org/10.1378/chest.121.4.1149

14. Oncel MY, Arayici S, Uras N et al (2016) Nasal continuous positive airway pressure versus nasal intermittent positive-pressure ventilation within the minimally invasive surfactant therapy approach in preterm infants: a randomised controlled trial. Arch Dis Child Fetal Neonatal Ed 101:F323-F328. https://doi.org/10.1136/archdischild2015-308204 